\title{
RESTORATION OF RUQYAH COVERS (MANUSCRIPT OF KITAB AL- TIBB BY IBN SINA)
}

Reda Farag ISMAIL *

Restoration Department, TBC, Lebanon.

\begin{abstract}
Parchment is considered one of the important materials in the manufacture of ancient manuscripts, and the use of parchment spread in the 3rd century AD (Reed 1975), and with people getting used to making parchment and using it in manuscripts, the quality, types and forms of parchment increased, as well as its uses, including manuscript covers. Paper replaced parchment with the 14th and 15th century parchment was given a good packaging material in terms of durability and formality, since with the spread of printing in $1550 \mathrm{AD}$ in Europe and the adoption of paper as a basic material for printing, parchment makers tended to use it as a packaging material that can be drawn on and printed as well. The use of parchment in binding in terms of the arrangement of the binding steps did not differ much from leather as a basic binding material in general, but the parchment reinforcement strips technique, in which parchment was used as supporting strips inside the covers called Laced, were thin strips of thickness affixed to the heel of the manuscript and placed these The strips are inside both covers. This technique was used most of the covers in early medieval parchment scrolls.

Keywords

Restoration, Ruqyah Covers, Manuscript, Kitab Al-Tibb, Ibn Sina.
\end{abstract}

\section{Introduction}

The cover of the Book of Law in Medicine is an ideal example of this technique, which was printed and perpetuated in Rome - Italy, written by Hussein Abdullah bin Ali, known as President Ibn Sina, who died in 428 AH. This book was printed in 1593 AD corresponding to $1100 \mathrm{AH}$ and it was authored it is The science of logic, natural science, and theology, and it was mentioned at the beginning of the book that some of his brothers and sisters asked him to help him to classify a book in medicine that includes its total and partial laws to explanation and abbreviation in medical colloquial matters, the theoretical part of them and the scientific part thereof, as well as in individual medicines and anatomy and this The book is indexed in Dar Al Kutub under the category of Medicine Group, No. 452 Private, the first publications dated 1895 A.D. The book dimensions are approximately $35 \times 45 \mathrm{~cm}$. The cover of this book was high from the natural factors of damage that led to dimensional shrinkage and dent in some parts, with poor storage conditions that led to laceration of the edges, loss of plot and scratches, in addition to many water stains and iron rust from metal shelves with dirt dirt and sintered end to Soltip adhesion, which necessitated action Cleaning, restoring and moisturizing the cover for reuse.

*Corresponding author: reda.farag@gmail.com 


\section{Deterioration Forms: Description of the manifestations of damage to the first paper cover:}

The book was exposed to many natural and human factors of damage in addition to extremely poor storage conditions and resulted in the following manifestations of damage:

1- The vertical position of the book leads to your top in the cover of the book and the edges of the binding and the damage and loss of the binding plot.

2- The book was exposed to stains of infectious rust, to put the book on metal shelves, where the metal shelves are highly conductive, which makes the parchment that is in contact with its surface more vulnerable to being affected by thermal changes in the surrounding atmosphere, as one of the damage factors affecting manuscripts and paper materials are thermal changes as parchment is a hygroscopic material It is highly vulnerable to the changes around it in the atmosphere, and the thermal changes over time lead to oxidation and hydrolysis of collagen, as well as the spread of rust spots to accelerate the rate of erosion of parchment and raise the rate of acidity, as it gave a reading of the $\mathrm{pH}$ rate of the rust surface $\mathrm{PH} 4.8$.

3- An old restoration work in which PVA adhesive was used in a large proportion, which led to an apparent damage to the lined carton.

4- The emergence of insect damage in the form of shallow holes and tunnels with the carton holder, which leads to the spread of insect infestation and the presence of poor storage conditions suitable for it.

5- $\quad$ Shrinkage and dryness in all dimensions of the casing, which also led to a clear damage to the gilding layer used in making parchment decorations.

6- $\quad$ Dirt on the surface of the parchment and helped to adhere to the parchment surface by the presence of high humidity, which leads to the transformation of the parchment to a yellowish-brown color.

7- Sharp cuts in the inner connective ligaments of the parchment, the spread of some breaks in the casing.

8- $\quad$ The presence of a sticker directly affixed to the surface of the archaeological parchment to indicate the number of the preservation of the book. Its $\mathrm{pH}$ was measured and found to be high for the $\mathrm{pH}$ value of 4.74 .

9- The presence of many scratches scattered throughout the surface of the cover, which confirms its exposure to a rough surface.

10- The presence of old adhesives inside the parchment in a dense form that spreads and adheres to the pores of the parchment.

11- The high acidity rate of the carton used in the cover, which gave high $\mathrm{pH}$ values of 
PH5.78, as well as the inner lining paper gave the values of PH 6.1.

The stages of the restoration process followed by the restoration steps:

\section{Cleaning:}

- Mechanical cleaning with a brush to remove dust.

- Mechanical cleaning with scalpels to remove old tape residue.

- Conducting a wet cleaning using alcohol + neutral soap at a rate of $1 \%$ dissolved in distilled water on the whole surface of parchment, then a mixture of white oil was used for the entire surface of the parchment $(50 \%+50 \%$ Evil alcohol, taking into account the change of blotting below the parchment several times.

- Solitip has been cleaned and removed using wet cotton swabs to torture trichlorethylene, as the solitip leaves adhesives that leave a sticky surface consisting of cellulose acetate that leads to the transparency of parchment and raising the acidity rate.

\section{Preparing the materials used to restore the first paper cover:}

1- Natural parchment (vellum): it is the parchment of calves embryos and it was prepared according to the common recipes of the medieval parchment industry. (1972 Cains. A 1992) (Reed. R) mentioned that this type of leather source gives thin parchment Strong with excellent physical properties.

2- $\quad$ Parchment glue (1992 (Wouters) and (2000 Stuarge.T) gave recipes for preparing parchment glue from parchment after cutting it into small pieces and then soaking it in water for 24 hours by boiling 21 grams of parchment in 2.5 liters of water for 45 minutes. Accurate and boil at a constant temperature inside a water bath, then the extract is filtered and used and applied while warm to maintain its high ability to penetrate into the pores and thus increase the required adhesive force.

3- Carboxymethylcellulose (CMC) is an aqueous ubiquitous cellulosic ether symbolized by the symbol CMC, and the pure type is white to pale yellow without taste and smell It is commercially available in degrees that dissolve in water and its degree of solubility varies according to partial weights. It is a substance miscible in water.

Individualization and humidification Conducting the process of moistening and individualizing the parchment to return to its original dimensions and to give it some of its lost elasticity properties for re-use on the print, and for this, a wooden frame + metal wrenches were lined from the inside using thick neutral paper to reduce the pressure on parchment, as I described this frame ( 2004 Riccardi. M) Moisturizing was performed in a simplified manner under the influence of the intensity that was implemented in the restoration laboratory, as parchment was a leather product that was prepared after treatment in an alkaline solution and was diluted under 
the influence of tension as well as the rest of the finishing stages, and then the collagen fibers that formed the parchment were transformed from the tubular form of the fibers They are stacked randomly into a very thin parallel surface stripe (Vorst. B 2006) and (1972 Reed. R). (1994 Turner. N) asserted that when the softening process is carried out, it must be under the same effect of the stretching process so that the parchment does not shrink, due to its natural need to return to its original position before drying, and this is done when it is exposed to moisture. Berardi (1992) confirmed that the parchment changes in dimensions. By 4. 5\% when exposed to moisture. Gore - Tex was used to re-moisturize the surface of parchment, as it helps to moisten the surface of parchment without condensing water droplets on its surface, which leads to the occurrence of wetness and stains of parchment, as it gives the parchment only moisture until it reaches a degree of saturation as confirmed by Banik (1992) and (Lee 1992) L) This is due to the small pores of the GoreTex fabric and the degree of high surface tension of the water, and a layer of holly-tex fabric is applied, then a layer of Gore-Tex and it is covered with a layer of wet blotting in the form of a sandwich covered with polyethylene, taking care not to pressure the sandwich while working with it for a period of time. About 3 hours (Singer H 1992). The table shows a picture of the layers of the compress

\section{Stages of the necessary maintenance process that was followed:}

\section{- $\quad$ First - cleaning:}

- Mechanical cleaning with a brush to remove dust.

- Conducting a wet cleaning using alcohol $+2 \%$ neutral soap for the entire surface of the parchment, using pieces of rolled cotton to remove the dirt attached to the parchment surface and its pores.

- A piece of cotton wrapped with pure alcohol was used.

- The cleaning of the surface of the casing was carried out in gradual stages to notice the difference, as well as the state of parchment improvement after cleaning. The measurement of the acidity of the parchment surface was 5.33 before cleaning. And by using a solution of neutral soap $2 \%$, then the cleaning was followed by a process of cleaning the traces of soap with pure alcohol, which measured SWAB 6.0. This was also confirmed by Munn 1994. J, et al. After cleaning, the $\mathrm{pH}$ of the parchment surface was measured at 5.66. During cleaning and after removing the dirt layer, it became clear that the parchment surface was covered with a sticky yellow layer, which is a covering layer of egg yolk with animal glue, which was used to cover the parchment surface in the followed finishing processes. Especially for the parchment used in book covers, and it has been handled with care so as not to be damaged. 


\section{Discussing the results:}

1- The historical study of manuscript making and standardization techniques helps in understanding cases of manuscript damage and then restoring it on a sound scientific basis and the old industry technique.

2- $\quad$ Preserving the valuable possessions of parchment needs good storage conditions like other important collectibles.

3- It is preferable to use simple chemically neutral substances when dealing with slavery, as it is sensitive to any additives.

4- The process of relaxing and moistening the parchment must be performed under the influence of tension to preserve the original dimensions of the parchment.

5- The processes of cleaning the surface of parchment help in reducing the high rates of acidity, as rust, soluble stains and old restoration as well as the accumulation of dust loaded with acidic gas oxides help in raising the acidity rates of roads, which speeds up the rates of aging, which must be followed by a preventive maintenance procedure Which helps to preserve the manuscript and not to strip the damage again.

\section{References:}

1- Boal G; A stitch In Time; Repairing The Original Sewing Structure On Bound Materials, In : The Book And Paper Group . vol 23, 1994.

2- Boyd-alkaly. E; the conservation of the Dead Sea scrolls in the laboratories of the Israel antiquates authority in Jerusalem. In: Restaurator Germany, 1997.

3- Brian J.Baired; Treatment 305: A Collections conservation approach to rebinding laced-on-board binding structures, in: the Book and paper group vol 23, 1994.

4- Dogrynina.E,\&Bykova.G., Study and conservation of the fourteenth century illuminated Greek manuscript' Akatisitus to the virgin' (Syn: cod. Gr.429) in: IPC conference paper London 1997,pp 200-205.

5- Munn. J, et al; Paper conservation catalog, Parchment Treatments, surface cleaning, by: Book and Paper Group, 9th edition, Copyright AIC/BPG. 1994, pp36-37.

6- Pamela Barrios; A stitch in time: Repairing the original sewing structure on board materials, a cautions approach to the repair of sewing, In: the book and paper group, annual 23, 2004 .

7- Pamela Spitzmueller; A stitch in time: In situ repair sewing of parchment tex blocks, In: the book and paper group, 2004.

8- $\quad$ Reed, R., Ancients skins, Parchments and leathers, Seminar Press, London, 1972.

9- $\quad$ Reed. R; The Nature and Making of Parchment, Leeds Element press, 1975. 
10- Reed, R; Parchment Old and New. paper conference on leather and parchment, London Sweden, 1978 .

11- Riccardi. M and Pinzari. F, A Guide To The Museum, Istituto Centrale Di Patologia Del Libro, conservation and restoration, Roma, 2004, p.51.

12- Rosa, H; Parchment (Report On The Conservation And Scientific Methods developed in the laboratory of paper and leather conservation ,Copernicus University. Poland In: Pergament, Germany.1991.

13- Szirmai. J.A, Old bookbinding techniques and their significance for book restoration, Drawing, neath, 1991, p.5.

14- Szirmai, J. A. The Archaeology of Medieval Bookbinding. Aldershot, U.K. Ashgate. 1999.

15- Stuarg T; Conservation of Leather Artifacts, Leather Conservation Center England, 2000 .

16- Timar .B; Protein binding media. In: Iccrom, Australia. 1993.

17- Vorst. M; Mysterious Vellum, fine print, Vol. 12, 2006 p.14

18- Wouters. J: The Conservation Of The Codex Eyckensis :The Evaluation Of The Project And The Assessment Of Materials And Adhesives For The Repair Of Parchment In: The Paper Conservator, vol. 16, 1992.

Received: February 8, 2018

Accepted: April 21, 2018 